\title{
Simple glucose reduction route for one-step synthesis of copper nanofluids
}

\author{
U. Sandhya Shenoy • A. Nityananda Shetty
}

Received: 6 September 2012/ Accepted: 13 October 2012/Published online: 25 October 2012

(C) The Author(s) 2012. This article is published with open access at Springerlink.com

\begin{abstract}
One-step method has been employed in the synthesis of copper nanofluids. Copper nitrate is reduced by glucose in the presence of sodium lauryl sulfate. The synthesized particles are characterized by X-ray diffraction technique for the phase structure; electron diffraction X-ray analysis for chemical composition; transmission electron microscopy and field emission scanning electron microscopy for the morphology; Fourier-transform infrared spectroscopy and ultraviolet-visible spectroscopy for the analysis of ingredients of the solution. Thermal conductivity, sedimentation and rheological measurements have also been carried out. It is found that the reaction parameters have considerable effect on the size of the particle formed and rate of the reaction. The techniques confirm that the synthesized particles are copper. The reported method showed promising increase in the thermal conductivity of the base fluid and is found to be reliable, simple and cost-effective method for preparing heat transfer fluids with higher stability.
\end{abstract}

Keywords Copper - Nanofluids - Nanoparticles · Thermal conductivity

\section{Introduction}

The thermal conductivity of heat transfer fluids plays an important role in the development of energy-efficient equipments in the field of microelectronics, transportation, military devices and biomedical industry (Liu et al. 2006;

U. S. Shenoy · A. N. Shetty $(\bowtie)$

Department of Chemistry, National Institute of Technology

Karnataka, Surathkal, Mangalore 575025, Karnataka, India

e-mail: nityashreya@gmail.com
Zhu et al. 2004a). Nanofluids have a plethora of potential tribological and magnetic sealing applications (Battez et al. 2010; Mitamura et al. 2008; Anwar et al. 2011). The low thermal conductivity of the conventional base fluids like water, ethylene glycol, engine oil acts as a major drawback in meeting the ever increasing demand for cooling (Zhu et al. 2004a). Hence, there is a need for devising heat transfer fluids with appreciably higher thermal conductivity. A straightforward way would be to suspend metallic or nonmetallic particles or their oxides which have nanodimensions. These particles have thermal conductivity higher than the base fluid and hence their incorporation would augment the heat transfer properties (Zhu et al. 2004a; Eastman et al. 2001). Since nanoparticles have large surface area, its interaction with the surrounding medium can overcome the difference in density and hence can remain stably suspended. The nano-size of the particles also overcomes the drawbacks of microparticles such as clogging of the channels, abrasion and pressure drop (Kumar et al. 2009).

Several studies, including the earliest investigations of nanofluids, used a two-step synthesis process in which nanoparticles are first produced as a dry powder, often by inert gas condensation, chemical vapor deposition, physical vapor deposition, mechanical alloying or other techniques (Chopkar et al. 2006; Das et al. 2003; Hong et al. 2005; Li et al. 2009). The nanoparticles are then dispersed into a fluid in a second processing step. Simple techniques such as ultrasonic agitation, control of $\mathrm{pH}$ or the addition of surfactants to the fluids are sometimes used to minimize particle aggregation and improve dispersion behavior (Beck et al. 2010; Hong et al. 2005; Li et al. 2008).

One-step method involves the production and simultaneous dispersion of the nanoparticles into the base fluid. It could be single-step physical method or chemical method. 
The earliest physical methods involve direct evaporation technique or vacuum evaporation on running oil substrate in which the evaporated metal is condensed when it comes in contact with the base fluid (Akoh et al. 1978; Eastman et al. 2001). Submerged arc nanoparticle synthesis and arc spray nanoparticle synthesis, which involve the vaporization of source material submerged in the dielectric liquid in a vacuum chamber, are the widely used techniques to produce metal and metal oxide nanofluids (Chang et al. 2005; Lo et al. 2005a, b). Laser ablation in liquid has been demonstrated to be the technique which can generate stable colloids containing nano-sized particles without the use of any dispersants or surface reactive reagents by ablating metals and metal oxides in deionized water and solvents (Kim et al. 2009; Phuoc et al. 2007).

Among the several approaches for the synthesis of nanofluids, the one-step chemical method is found to be the one which can overcome the downsides of other techniques like agglomeration during storage, partial dispersion, need for liquids with high-boiling points and expensive equipments (Zhu et al. 2004a; Eastman et al. 2001; Kumar et al. 2009). Literature reveals that there are only a few reports on this technique (Kumar et al. 2009; Liu et al. 2006; Zhu et al. 2004a). Herein, we follow a simple single-step chemical solution phase approach for the synthesis of copper nanofluids. Copper nitrate is used as the precursor and glucose as reducing agent, in the presence of sodium lauryl sulfate (SLS). Thermal and rheological properties of the fluids have also been studied.

\section{Experiment}

Preparation of nanofluids

All the reagents used in the experiment were of analytical grade and were used without further purification. Copper nanofluids were prepared by solution phase synthesis, by reduction of copper nitrate using glucose. In a typical procedure, $30 \mathrm{~mL}$ of $0.1 \mathrm{M}$ aqueous solution of copper nitrate trihydrate was rendered ammoniacal by adding ammonium hydroxide (5 $\mathrm{mL}$ of $2 \mathrm{M}$ solution) till the color became deep blue. Later, the solution was stirred with $30 \mathrm{~mL}$ of $0.01 \mathrm{M}$ solution of SLS in ethylene glycol. After $15 \mathrm{~min}, 3 \mathrm{~g}$ of glucose was added and stirred at $75^{\circ} \mathrm{C}$ till the color changed to golden yellow. At this point, sulfuric acid was added to neutralize the added ammonium hydroxide. When the color turned brown, the solution was cooled to get copper nanofluid. The synthesis was repeated by varying the concentration of reducing agent, surfactant and dilution. The reduction was also carried out under microwave irradiation. The solution was subjected to microwave radiation for $5 \mathrm{~min}$ at $50 \%$ power. The synthesis under microwave condition was carried at different reactant ratio, power and reaction time.

\section{Characterization}

The synthesized nanofluids were characterized by X-ray diffraction (XRD) technique, energy dispersive X-ray analysis (EDXA), transmission electron microscopy (TEM), field emission scanning electron microscopy (FESEM), Fourier-transform infrared (FTIR) spectroscopy and UV-visible spectroscopy. Thermal conductivity and viscosity measurements were also carried out.

Nanofluid was diluted with absolute ethanol and centrifuged for $1 \mathrm{~h}$. The nanoparticles were then repeatedly washed with water and ethanol. Finally, the particles were dried at $80{ }^{\circ} \mathrm{C}$. XRD patterns of the nanoparticles were taken on a JEOL X-ray diffractometer (Model DX GE 2P) using Ni-filtered $\mathrm{Cu}-\mathrm{K}_{\alpha}$ radiation $(\lambda=1.54178 \AA$ ) with an operating voltage of $30 \mathrm{kV}$. The accelerating voltage was set at $0.06^{\circ} \mathrm{s}^{-1}$ in the $2 \theta$ range $35^{\circ}-80^{\circ}$.

The TEM images of the nano fluids were recorded on a Philips CM200 transmission electron microscope operating with an accelerating voltage of $20-200 \mathrm{kV}$ with a resolution of $2.4 \AA$. The FESEM images were taken on a Supra 40VP FESEM having a resolution up to $2 \mathrm{~nm}$. EDXA was carried out using JEOL JSM-6380LA analytical scanning electron microscope.

The ingredients of the solution were identified using Nicolet Avatar 330 FTIR spectrometer. UV-visible spectra of the nanofluids were measured using SD2000 fiber optic spectrometer from Ocean optics inc., at room temperature. The thermal conductivity of the prepared nanofluid was measured using KD2 Pro thermal property analyzer. The viscosity of the nanofluids was measured using Brookfield LV DV-III ultra rheometer.

\section{Results and discussion}

\section{Results of XRD and EDX analyses}

The phase structure and the purity of the products were examined by XRD studies. The XRD powder pattern of the as-obtained copper nanoparticles is shown in Fig. 1. The diffraction peaks could be indexed to the face centred cubic $\mathrm{Cu}$ [JCPDS Card No. 04-0838, $a=3.6150 \AA$, space group: Fm3m (225)] corresponding to (111), (200) and (220) planes, respectively.

The average size of the particle is calculated using Scherrer's formula (West 1989):

$$
\tau=\frac{K \lambda}{B \cos \theta}
$$




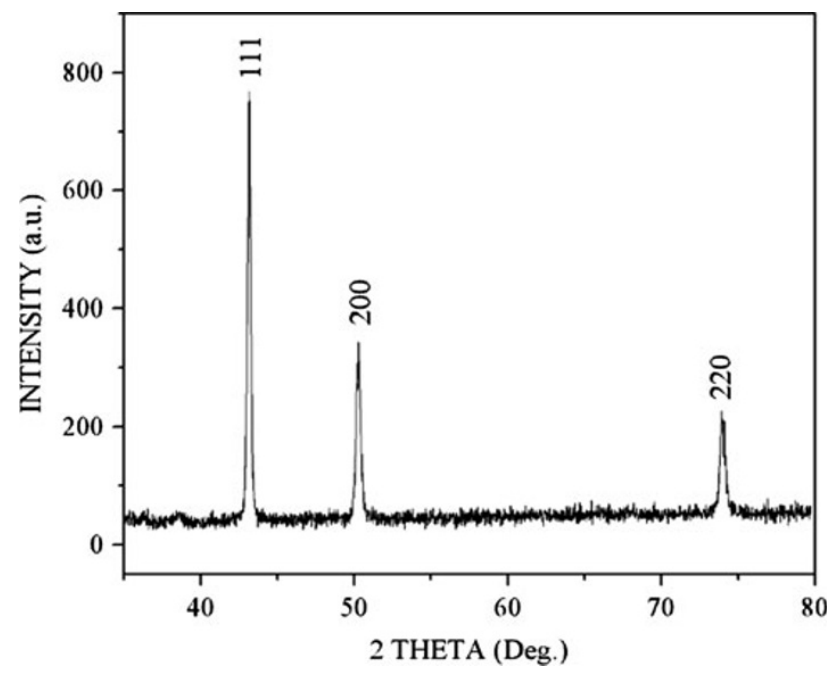

Fig. 1 A typical XRD powder pattern of copper nanoparticles

where $\tau$ is the thickness of the crystal (in $\AA$ ), $K$ the shape factor, $\mathrm{X}$-ray wavelength is given by $\lambda$ and Bragg angle by $\theta$. The line broadening, $B$ is measured from the extra peak width. All the particle size data reported in the paper are as calculated above. No peaks of impurities such as those of cuprous or cupric oxide were detected, suggesting that the product obtained was highly pure.

The chemical composition and purity of the products were also examined using EDXA. A typical EDX spectrum of the copper nanoparticles is shown in the Fig. 2. Only copper is detected in the spectrum indicating that there is no contamination.

\section{Results of FTIR and UV analyses}

The FTIR spectra of pure ethylene glycol (A) stacked with copper nanofluid (B) are shown in Fig. 3. It is seen that the two spectra resemble each other indicating that ethylene glycol is not oxidized. It suggests that glucose is the one acting as reducing agent and not ethylene glycol. This method preserves the advantages of the polyol process as well as chemical reduction method. Figure 4 shows UV-vis spectrum of copper nanofluid. The absorption edge at $544 \mathrm{~nm}$ indicates the peak due to copper nanoparticles (Bicer and Sisman 2010).

Results of variation in reaction parameter

\section{Effect of ratio of reactants}

The synthesis was carried out by varying the molar ratio of glucose to copper nitrate. The increase in molar ratio from 5.5 to 18.5 resulted in particles having sizes decreasing from 36 to $17 \mathrm{~nm}$ in thermal conditions and 28 to $16 \mathrm{~nm}$ in microwave conditions, respectively. Glucose reduces copper ions as shown in Eq. (2).
$\mathrm{Cu}^{2+}+\mathrm{C}_{6} \mathrm{H}_{12} \mathrm{O}_{6}+\mathrm{H}_{2} \mathrm{O} \rightarrow \mathrm{Cu}+\mathrm{C}_{6} \mathrm{H}_{12} \mathrm{O}_{7}+2 \mathrm{H}^{+}$

According to the above equation, the concentration of glucose determines the amount of electrons supplied to copper ions and in turn the rate of the reaction. When the concentration of the reducing agent is low, the reduction rate of copper precursor is slow and, as a result, only a few nuclei are formed at the nucleation step. Copper atoms formed at the later period, are mostly involved in particle growth by collision with already generated nuclei leading to the formation of larger-sized particles, rather than formation of new particles. With increase in concentration of reducing agent, reduction rate is enhanced, so the number of precipitating metallic clusters increases steeply and hence more number of nuclei is formed during the nucleation period which leads to the formation of smaller particles. Eventually, the size of the particles decreases because the amount of solute available for particle growth per growing particle decreases with increasing number of nuclei (Park et al. 2007).

Figure 5 shows FESEM image of the copper nanoparticles obtained when $30 \mathrm{~mL}$ of $0.1 \mathrm{M}$ copper nitrate solution is reduced by $3 \mathrm{~g}$ of glucose in the presence of $0.01 \mathrm{M}$ SLS solution, and its inset shows the TEM image of a single particle present in the nanofluid. The particles appear somewhat spherical in shape.

\section{Effect of addition of ammonia}

The synthesis of copper nanofluid is carried out in the presence of ammonia. Most of the copper ion is therefore present as $\mathrm{Cu}\left(\mathrm{NH}_{3}\right)_{2}^{2+}$ complex ion. The standard half-cell potential for the reduction of copper ion as given in Eq. (3) is $0.34 \mathrm{~V}$. The half-cell potential for the reduction of $\mathrm{Cu}\left(\mathrm{NH}_{3}\right)_{2}^{2+}$ complex ion is considerably smaller than that for reduction of $\mathrm{Cu}^{2+}$ ion.

$\mathrm{Cu}^{2+}+2 \mathrm{e}^{-} \rightarrow \mathrm{Cu}$

The standard half-cell potential for the redox equilibrium of glucose given in Eq. (4) is $0.050 \mathrm{~V}$.

$\mathrm{C}_{6} \mathrm{H}_{12} \mathrm{O}_{7}+2 \mathrm{H}^{+}+2 \mathrm{e}^{-} \leftrightarrow \mathrm{C}_{6} \mathrm{H}_{12} \mathrm{O}_{6}+\mathrm{H}_{2} \mathrm{O}$

The overall standard state cell potential for the reaction given in Eq. (2) is $0.29 \mathrm{~V}$ and hence favorable. There is a significant decrease in the overall cell potential for the reaction in the presence of ammonia because the complex ion is a much weaker oxidizing agent than the $\mathrm{Cu}^{2+}$ ion.

The increase in $\mathrm{pH}$ of the solution due to the addition of ammonia has an effect on the electrode potential of the glucose system, because of a pair of $\mathrm{H}^{+}$ions involved. The half-cell potential for the redox equilibrium of glucose therefore depends on the $\mathrm{pH}$ of the solution. The reaction quotient for this reaction depends on the square of $\mathrm{H}^{+}$ion 
Fig. 2 A typical EDX spectrum of copper nanoparticles

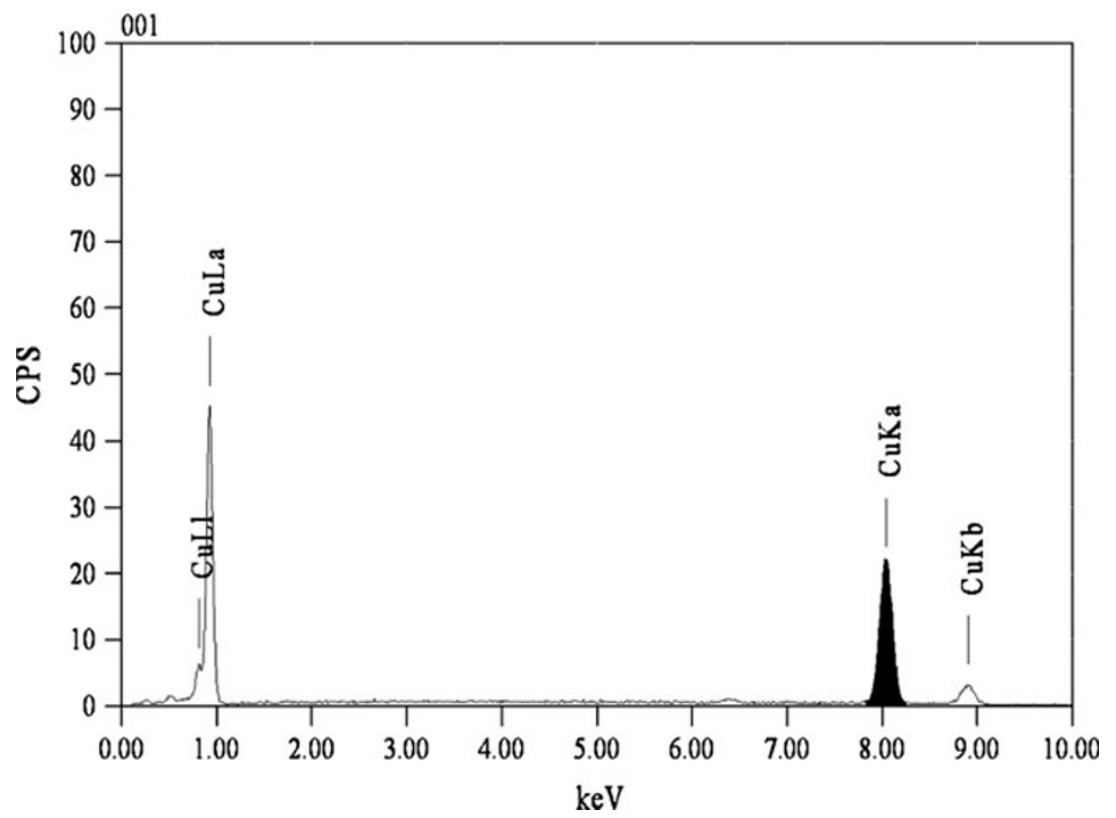

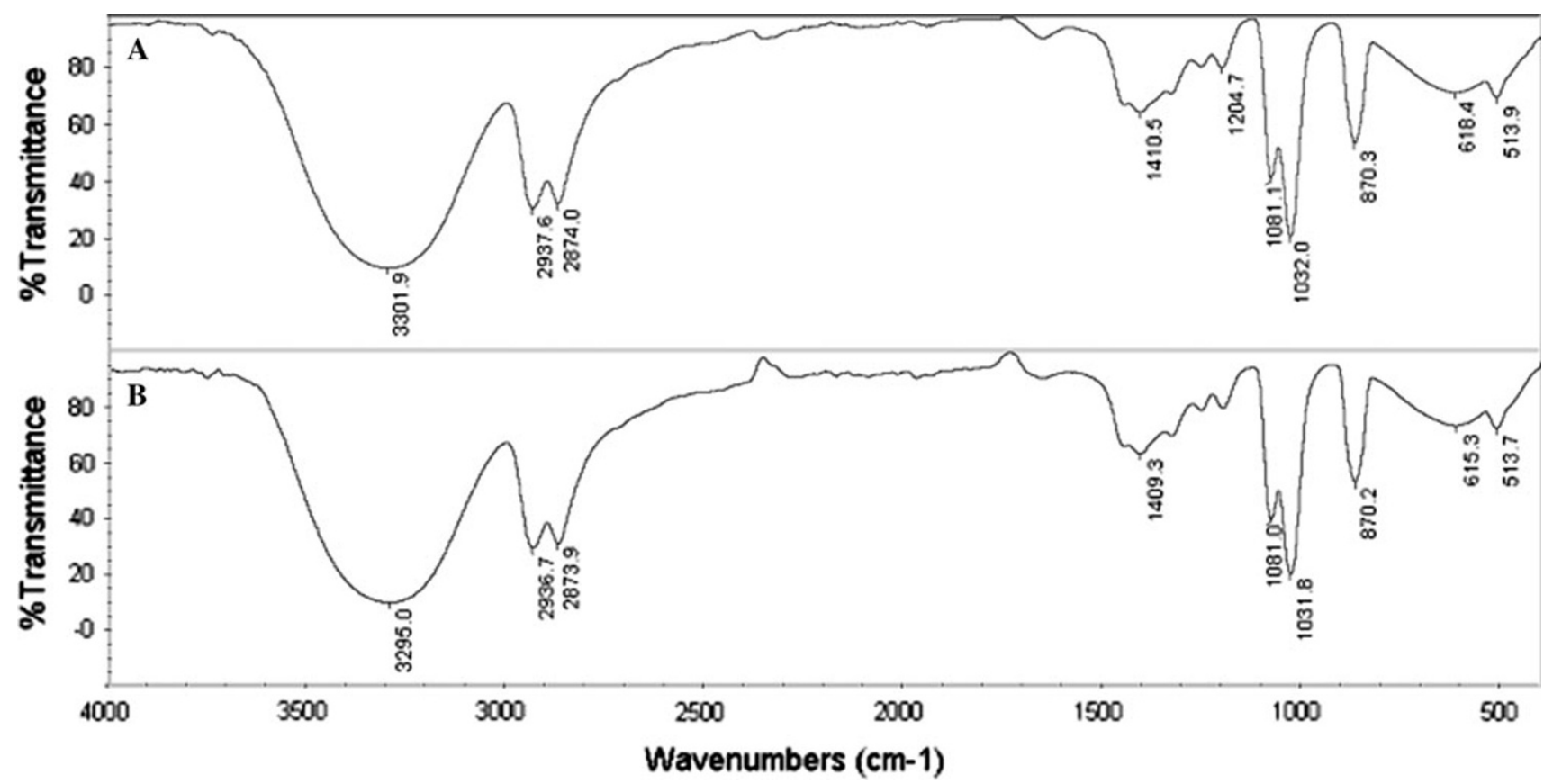

Fig. 3 FTIR spectra of ethylene glycol (a) and copper nanofluid (b)

concentration as two $\mathrm{H}^{+}$ions are given off when glucose is oxidized. A change in solution $\mathrm{pH}$ from standard state conditions to $\mathrm{pH}$ of 11 , therefore, results in a decrease of half-cell potential for this reaction and increase in the reducing strength of glucose. This increase more than compensates for the decrease in oxidizing strength of $\mathrm{Cu}^{2+}$ in the presence of ammonia. As the overall cell potential for the reduction of copper ions is more favorable in aqueous ammonia, the reaction is not carried under standard state conditions.

\section{Effect of dilution}

To study the effect of dilution on the particle size and rate of reaction, the reaction mixture was diluted with varying volumes of water. The particle size decreased with increase in amount of dilution from 0 to $100 \mathrm{~mL}$ of water. The particles yielded had 36, 35, 26 and $21 \mathrm{~nm}$ size for 0,50 , 75 and $100 \mathrm{~mL}$ dilution, respectively. For $100 \mathrm{~mL}$ dilution, the reaction proceeded very slowly due to the decrease in the effective concentration of the reacting species. The 


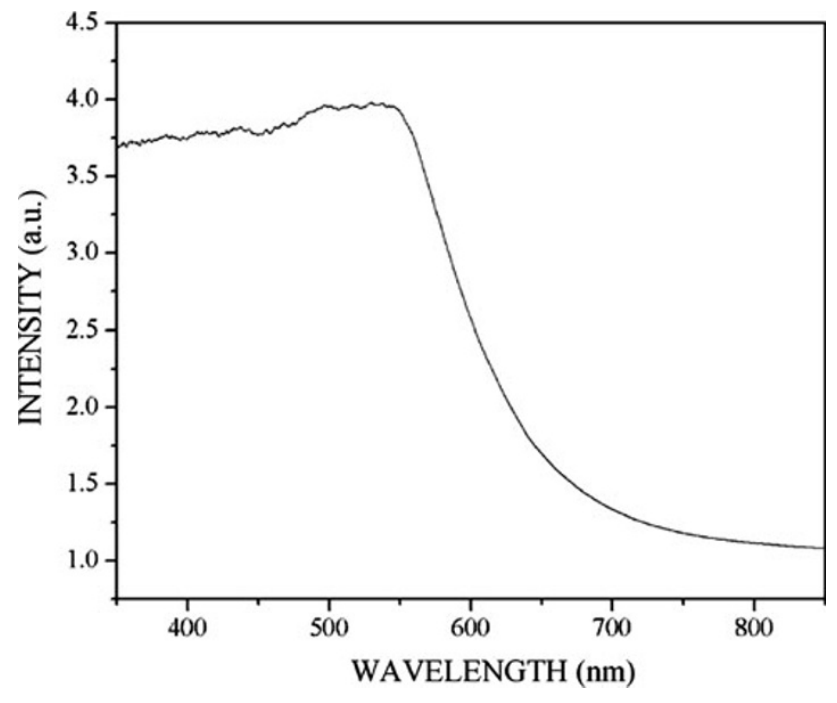

Fig. 4 UV-visible spectrum of copper nanofluid

observations can be explained as follows: with increase in the dilution, the overall concentration of the species decreases, the proximity between the precipitating metal atoms decreases and hence the collision between them is reduced preventing the particle growth and hence resulting in smaller size of the nanoparticles formed.

\section{Effect of surfactant}

Concentration of surfactant also played an important role in controlling the size of the particle as well as stability of the nanofluid. The effect of increase in surfactant concentration on size of the particle is shown in Table 1.

The results clearly indicate that SLS acts as a capping agent and hence restricts the growth of the particles. As the SLS concentration increases, the particle size decreases. The presence of surfactant also had an effect on the stability of the fluid. In the absence of surfactant, the particles formed immediately began to settle down, but in the presence of surfactant, this was not the case. Sedimentation measurements showed that the nanofluid prepared in the presence of surfactant was stable up to 3 weeks at room temperature under stationary state. The stability achieved is better than the one by the two-step method where in they could achieve it for 1 week in case of copper-transformer oil system and $30 \mathrm{~h}$ for copper-water system (Xuan and $\mathrm{Li}$ 2000). The stability of the fluid could be attributed to the small size of the particles and their uniform distribution.

\section{Effect of power and reaction time}

The reactions were carried out by irradiating the reaction mixture by microwave and effect of microwave power and reaction time were studied. For microwave irradiation of

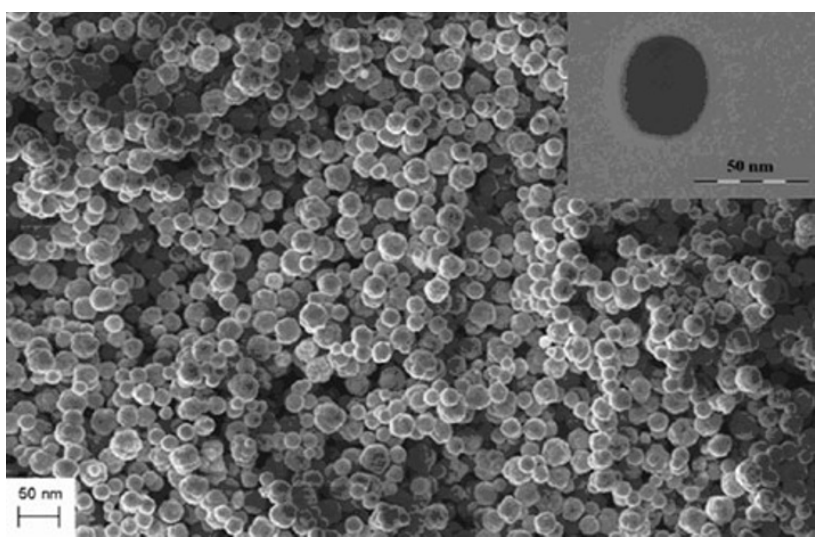

Fig. 5 Low-magnification FESEM image showing spherical copper nanoparticles. Inset shows a TEM image of a single particle

Table 1 Effect of concentration of SLS on size of copper particles

\begin{tabular}{lll}
\hline $\begin{array}{l}\text { Concentration of } \\
\text { SLS added }(\mathrm{M})\end{array}$ & $\begin{array}{l}\text { Effective concentration of SLS in } \\
\text { the reaction mixture }(\mathrm{mM})\end{array}$ & $\begin{array}{l}\text { Particle } \\
\text { size }(\mathrm{nm})\end{array}$ \\
\hline 0 & 0 & 58 \\
0.01 & 5 & 36 \\
0.05 & 25 & 28 \\
0.1 & 50 & 19 \\
\hline
\end{tabular}

$30 \%$ power for 5 min duration and for $50 \%$ power for duration of $2.5 \mathrm{~min}$, the reactions were incomplete, and size of the particles obtained was $20 \mathrm{~nm}$. As power was increased from 50 to 70 to $90 \%$ for 5 min irradiation time, the particle size was found to decrease from 28 to 25 to $19 \mathrm{~nm}$. In microwave method, the heating rate is faster than the conventional means. Microwave irradiation increases the rate of nucleation and results in the formation of large number of nuclei. With increase in power, the friction between the particles also increases, suppressing the ready growth of particles, hence the size of the formed particles is found to show decreasing trend. With increase in irradiation duration at $50 \%$ power, the size increased as follows: 28, 32 and $35 \mathrm{~nm}$ for $5,7.5$ and $10 \mathrm{~min}$, respectively. The continued interaction of the particles leads to growth of the particles resulting in larger size (Zhu et al. 2004b).

\section{Results of thermal conductivity measurement}

Thermal conductivity of the nanofluid was measured at $30{ }^{\circ} \mathrm{C}$ using KS-1 sensor. The sensor was oriented vertically in the sample and the measurements were recorded at low power mode with read time of $1 \mathrm{~min}$, with the sample and the sensor kept absolutely still during the measurement, to avoid forced convection. Measurements were done with different particle weight fractions by diluting the nanofluid with mixture of water and ethylene glycol in 1:1 ratio. 
Fig. 6 The variation of thermal conductivity ratio with nanoparticle weight fraction showing linear increase. Inset shows the variation over entire range

Fig. 7 Rheological

measurements. a The variation of shear stress with shear rate at $30{ }^{\circ} \mathrm{C}$ for a particle loading of $0.299 \%$. b Viscosity as a function of shear rate for $0.299 \%$ particle loading at different temperatures. Black right-pointing triangle $20^{\circ} \mathrm{C}$, black left-pointing triangle $25{ }^{\circ} \mathrm{C}$, black circle $30{ }^{\circ} \mathrm{C}$, black star $35^{\circ} \mathrm{C}$, black square $40{ }^{\circ} \mathrm{C}$, black down-pointing triangle $45{ }^{\circ} \mathrm{C}$, black up-pointing triangle $50{ }^{\circ} \mathrm{C}$. c Variation of relative viscosity of the nanofluid with particle weight fraction. d Variation of viscosity of the nanofluid with temperature

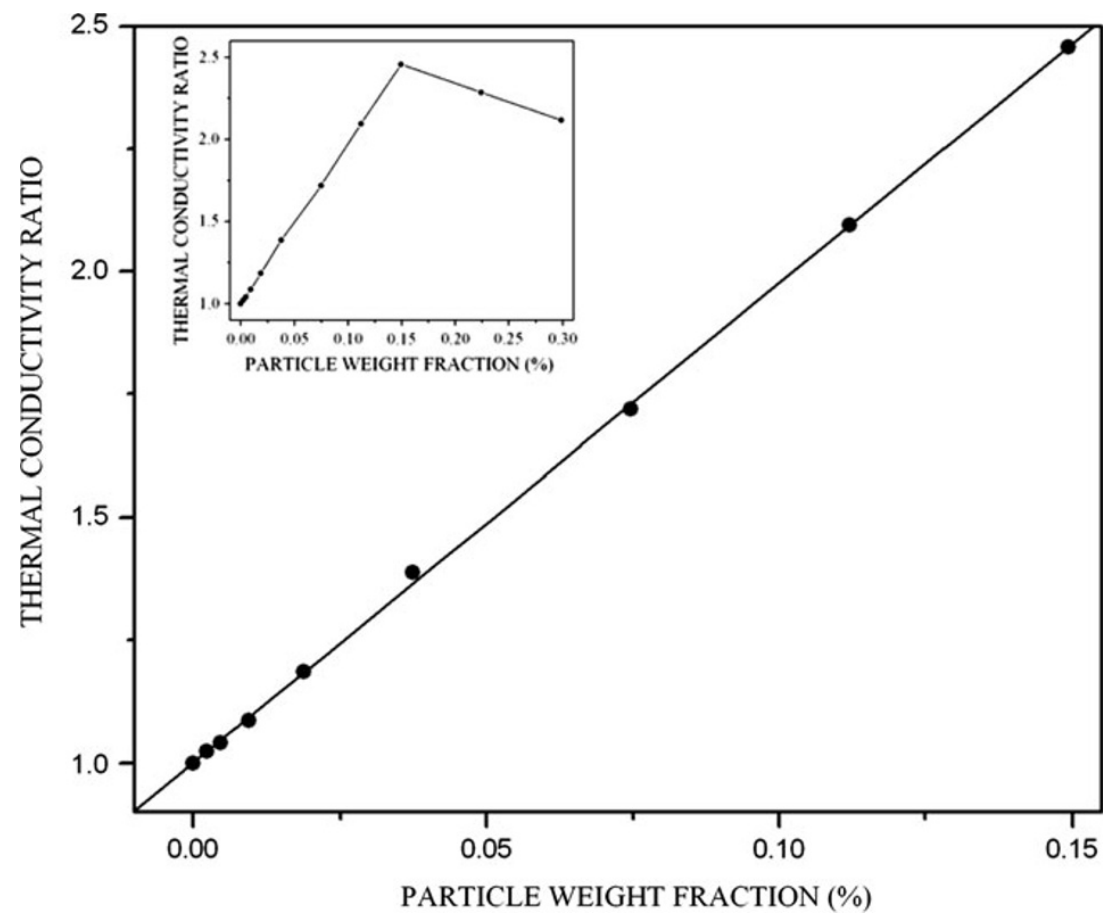

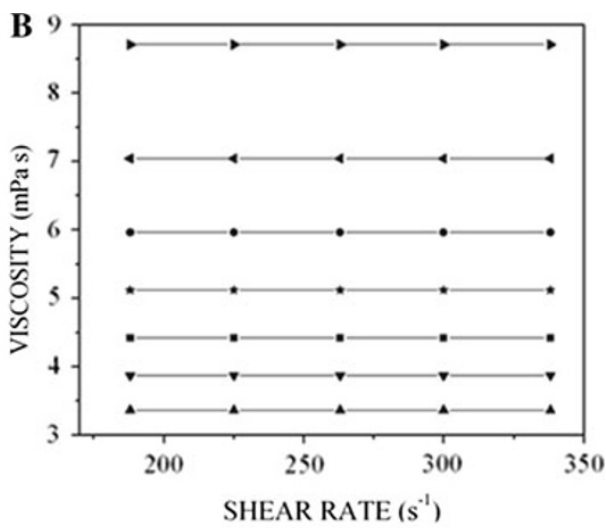

C

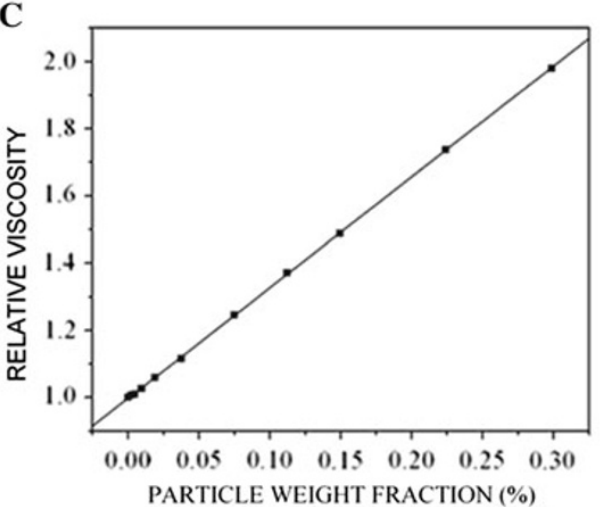

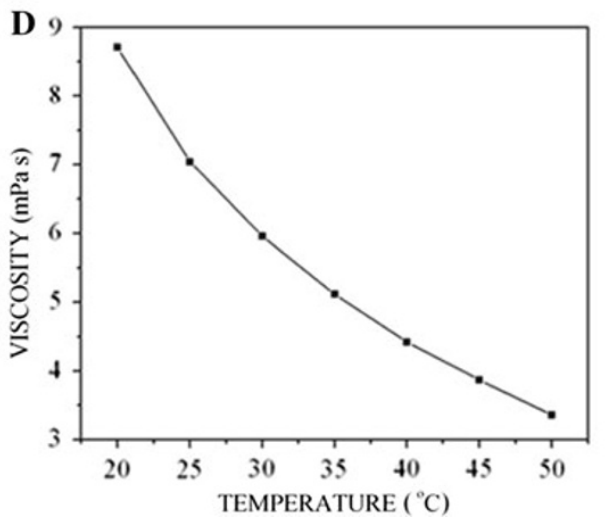

The thermal conductivity of the as-synthesized nanofluid was found to be $0.834 \mathrm{Wm}^{-1} \mathrm{~K}^{-1}$ for a weight fraction of $0.299 \%$, which is significantly higher than the reported value of $0.279 \mathrm{Wm}^{-1} \mathrm{~K}^{-1}$ for copper nanofluid $(0.1 \%)$ prepared using sodium hypophosphite (Zhu et al. 2004a) and $0.259 \mathrm{Wm}^{-1} \mathrm{~K}^{-1}$ for copper nanofluid $(0.5 \%)$ 
prepared by single-step physical method of direct evaporation technique (Eastman et al. 2001). The variation of thermal conductivity ratio with nanoparticle weight fraction is shown in Fig. 6. Similar trend was observed for different ratios of the base fluids.

The thermal conductivity of the nanofluid increased linearly with increase in the particle concentration. Maximum thermal conductivity of $0.968 \mathrm{Wm}^{-1} \mathrm{~K}^{-1}$ was observed at a particle weight fraction of $0.15 \%$; after this, the thermal conductivity showed a gradual decrease. This increase could be ascribed to the higher conductivity of copper nanoparticles as well as its uniform distribution in the fluid (Chopkar et al. 2006; Murshed et al. 2008).

\section{Results of rheological measurements}

The rheological measurements of the nanofluid were carried out at a particle weight fraction of $0.299 \%$. The variation of shear stress with shear rate at $30{ }^{\circ} \mathrm{C}$ is shown in Fig. 7a. The linear relation between the shear stress and shear rate demonstrates the Newtonian behavior of the nanofluid (Yu et al. 2009). Viscosity as a function of shear rate at different temperatures demonstrates that viscosity is independent of shear rate (Fig. 7b).

The viscosity of the nanofluids was also measured at different particle weight fractions at $30{ }^{\circ} \mathrm{C}$. The changes in relative viscosity of the nanofluid with particle weight fraction are given in Fig. 7c. It was found that the viscosity increased with increase in particle concentration. The effect of temperature on the viscosity of the nanofluid was studied from 20 to $50{ }^{\circ} \mathrm{C}$ and was seen that the viscosity decreases with increase in temperature of the fluid. The variation in the viscosity of the nanofluid with temperature is shown in Fig. 7d. The trend is similar to the one reported by Li et al. (2011).

\section{Conclusions}

Copper nanofluids were synthesized by a well-controlled one-step solution phase glucose reduction method. Herein copper nitrate was reduced to copper and was simultaneously dispersed in the base fluid, in the presence of SLS. The synthesized particles were characterized by various techniques. A stability period of minimum 3 weeks was achieved in the presence of surfactant. The synthesized fluid showed a maximum thermal conductivity of $0.968 \mathrm{Wm}^{-1} \mathrm{~K}^{-1}$ and exhibited Newtonian behavior. The method is found to be reliable, simple in approach and cost effective.

Open Access This article is distributed under the terms of the Creative Commons Attribution License which permits any use, distribution, and reproduction in any medium, provided the original author(s) and the source are credited.

\section{References}

Akoh H, Tsukasaki Y, Yatsuya S, Tasaki A (1978) Magnetic properties of ferromagnetic ultrafine particles prepared by vacuum evaporation on running oil substrate. J Cryst Growth 45:495-500

Anwar K, Han T, Kim SM (2011) Reversible sealing techniques for microdevice applications. Sens Actuators B 153:301-311

Battez AH, Viesca JL, Gonzalez R, Blanco D, Asedegbega E, Osorio A (2010) Friction reduction properties of a $\mathrm{CuO}$ nanolubricant used as lubricant for a NiCrBSi coating. Wear 268:325-328

Beck MP, Yuan Y, Warrier P, Teja AS (2010) The thermal conductivity of alumina nanofluids in water, ethylene glycol and ethylene glycol-water mixtures. J Nanopart Res 12:14691477

Bicer M, Sisman I (2010) Controlled synthesis of copper nano/ microstructures using ascorbic acid in aqueous CTAB solution. Powder Technol 198:279-284

Chang H, Tsung TT, Chen LC, Yang YC, Lin HM, Lin CK, Jwo CS (2005) Nanoparticle suspension preparation using the arc spray nanoparticle synthesis system combined with ultrasonic vibration and rotation electrode. Int $\mathrm{J}$ Adv Manuf Technol 26:552-558

Chopkar M, Das PK, Manna I (2006) Synthesis and characterization of a nanofluid for advanced heat transfer applications. Scr Mater 55:549-552

Das SK, Putra N, Roetzel W (2003) Pool boiling characteristics of nanofluids. Int J Heat Mass Transf 46:851-862

Eastman JA, Choi SUS, Li S, Yu W, Thompson LJ (2001) Anomalously increased effective thermal conductivities of ethylene glycol based nanofluids containing copper nanoparticles. Appl Phys Lett 78:718-720

Hong TK, Yang HS, Choi CJ (2005) Study of enhanced thermal conductivity of Fe nanofluids. J Appl Phys 97:064311-064314

Kim HJ, Bang IC, Onoe J (2009) Characteristic stability of bare Auwater nanofluids fabricated by pulsed laser ablation in liquids. Opt Lasers Eng 47:532-538

Kumar AS, Meenakshi KS, Narashimhan BRV, Srikanth S, Arthanareeswaran G (2009) Synthesis and characterization of copper nanofluid by a novel one step method. Mater Chem Phys 113:57-62

Li XF, Zhu DS, Wang XJ, Wang N, Gao JW, Li H (2008) Thermal conductivity enhancement dependent $\mathrm{pH}$ and chemical surfactant for $\mathrm{Cu}-\mathrm{H}_{2} \mathrm{O}$ nanofluids. Thermochim Acta 469:98-103

Li Y, Zhou J, Tung S, Schneider E, Xi S (2009) A review on development of nanofluid preparation and characterization. Powder Technol 196:89-101

Li D, Xie W, Fang W (2011) Preparation and properties of copper oil based nanofluids. Nanoscale Res Lett 373:1-7

Liu MS, Lin MCC, Tsai CY, Wang CC (2006) Enhancement of thermal conductivity with $\mathrm{Cu}$ for nanofluids using chemical reduction method. Int J Heat Mass Transf 49:3028-3033

Lo CH, Tsung TT, Chen LC (2005a) Shape-controlled synthesis of $\mathrm{Cu}$-based nanofluid using submerged arc nanoparticle synthesis system (SANSS). J Cryst Growth 277:636-642

Lo CH, Tsung TT, Chen LC, Su CH, Lin HM (2005b) Fabrication of copper oxide nanofluid using submerged arc nanoparticle synthesis system (SANSS). J Nanopart Res 7:313-320

Mitamura Y, Arioka S, Sakota D, Sekine K, Azegami M (2008) Application of a magnetic fluid seal to rotary blood pumps. J Phys Condens Matter 20:204-208 
Murshed SMS, Leong KC, Yang C (2008) Investigations of thermal conductivity and viscosity of nanofluid. Int $\mathrm{J}$ Therm Sci 47:560-568

Park BK, Jeong S, Kim D, Moon J, Lim S, Kim JS (2007) Synthesis and size control of monodisperse copper nanoparticles by polyol method. J Colloid Interface Sci 311:417-424

Phuoc TX, Soong Y, Chyu MK (2007) Synthesis of Ag-deionized water nanofluids using multi-beam laser ablation in liquids. Opt Lasers Eng 45:1099-1106

West AR (1989) Solid state chemistry and its applications. Wiley, Singapore
Xuan Y, Li Q (2000) Heat transfer enhancement of nanofluids. Int J Heat Fluid Flow 21:58-64

Yu W, Xie H, Chen L, Li Y (2009) Investigation of thermal conductivity and viscosity of ethylene glycol based $\mathrm{ZnO}$ nanofluid. Thermochim Acta 49:92-96

Zhu H, Lin Y, Yin Y (2004a) A novel one step chemical method for preparation of copper nanofluids. J Colloid Interface Sci 277:100-103

Zhu H, Zhang C, Yin Y (2004b) Rapid synthesis of copper nanoparticles by sodium hypophosphite reduction in ethylene glycol under microwave irradiation. J Cryst Growth 270:722-728 